\title{
RESEARCH OF THE PARAMETERS OF CUT FOR THE MACHINING
}

\section{OF THE NEW CONCRETES}

\section{A. CHAOUFI, A. TAFRAOUI, M. ZAOUI, S. TAFRAOUI \& M. DAHMANI}

Department of Mechanical Engineering, University TAHRI Mohamed BECHAR, Mechanical Engineering Reliability Laboratory, BP Bechar, Algeria.

\begin{abstract}
The composite materials are largely used (aeronautical), because of their advantageous mechanical properties (weight ratio/resistance). Because of the complexity of the phenomena presenting the zone of cut, current knowledge on their machining is limited and prevents their optimal use. From their constitution, these materials pose many problems during their machining. The objective of this study is to seek the parameters of cut during the composite machining of materials Concrete High efficiency (HPC) and Concrete Fiber High efficiency (HPCF). The latter are proposed for the manufacturing of the molds to carryout composite material parts, but the materials used for the manufacturing of the molds of the composite material parts like polyester, silicone and resin epoxy etc., do not resist to high temperatures, and also to analyze the behavior of the composite concrete during machining. Allowing to avoid the appearance of the defects (heating and wear of the cutting tool). An experimental design of machining of some tests was defined for the research of the parameters of cut (cutting speed Vc, depth of cut ap and advances by turn f). The variation of the parameters of cut for each test showed that machining after treatment, caused problems at particular level as in cutting tools and the appearance of the quoted defects.

KEYWORDS: Machining, HPC, HPCF, Mold, Composite Materials, Parameters of Cuts \& Surface Quality
\end{abstract}

Received: Sep 12, 2017; Accepted: Oct 02, 2017; Published: Nov 15, 2017; Paper Id.: IJMPERDDEC201736

\section{INTRODUCTION}

The composite materials today are largely used in many industrial sectors, such as aeronautics, automotive engineering, the nuclear power, the biomedical genius. The reasons of such success are to be allotted to their high specific mechanical characteristics. For this purpose, the whole of the manufacturers follows this trend in order tore main competitive and produce light errand more economic mechanisms. These materials take little by little the place of conventional materials such as aluminum alloys and make it possible, to carry out profits of consequent weights $[1,2,8,11,13$, and 15$]$.

As, the aeronautical parts of structure can be obtained by the manufacturing processes of family LCM (Composite Liquid Molding), this process imposes an operating temperature raised for the tools, about $180^{\circ} \mathrm{C}$ for a resin the epoxy, which leads to a dilation of the harmful mold to the dimensional quality of the die-casting, even use of the molds in to epoxy or out of wood does not resist a high treatment of composite part. $[4,5,7,9,10,12]$

A composite material concrete (HPC) or (HPCF) is proposed for the manufacturing of the molds, for the realization of the composite material parts. Then, the need for the research of the parameters of cuts, for the machining of these concrete molds is the object of this work. The problems of machining (HPC) and (HPCF) meets due to the heat treatment, to improve the mechanical characteristics, then several tests are carried out to 
determine these parameters of cut which are reached and illustrated in this article.

However, the optimization of the machining of composite material molds passes by the choice of the machine and the tools making it possible to lead to arrange productive and making it possible to reach expected quality.

Initially, the problems of the machining of the concrete molds are to determine the parameters of machining of the latter to knowing speed in advance, the penetration, and the cutting speed.

\section{MATERIALS AND METHODS}

\section{MATERIALS}

The materials used for the manufacturing of Concrete (HPC and HPCF) are: (Figure.1)

- $\quad$ Cement CEM42.5MPa (seetable1)

- Sand of dune of the erg of the area of Taghit (BECHAR)

- $\quad$ Sand of dune crushed with $80 \mu \mathrm{m}$

- $\quad$ Silica fume SIKAS95DM

- $\quad$ Super-plasticizer SIKA plast 5045

- $\quad$ Fiber (metal, synthetic, glass, carbon)

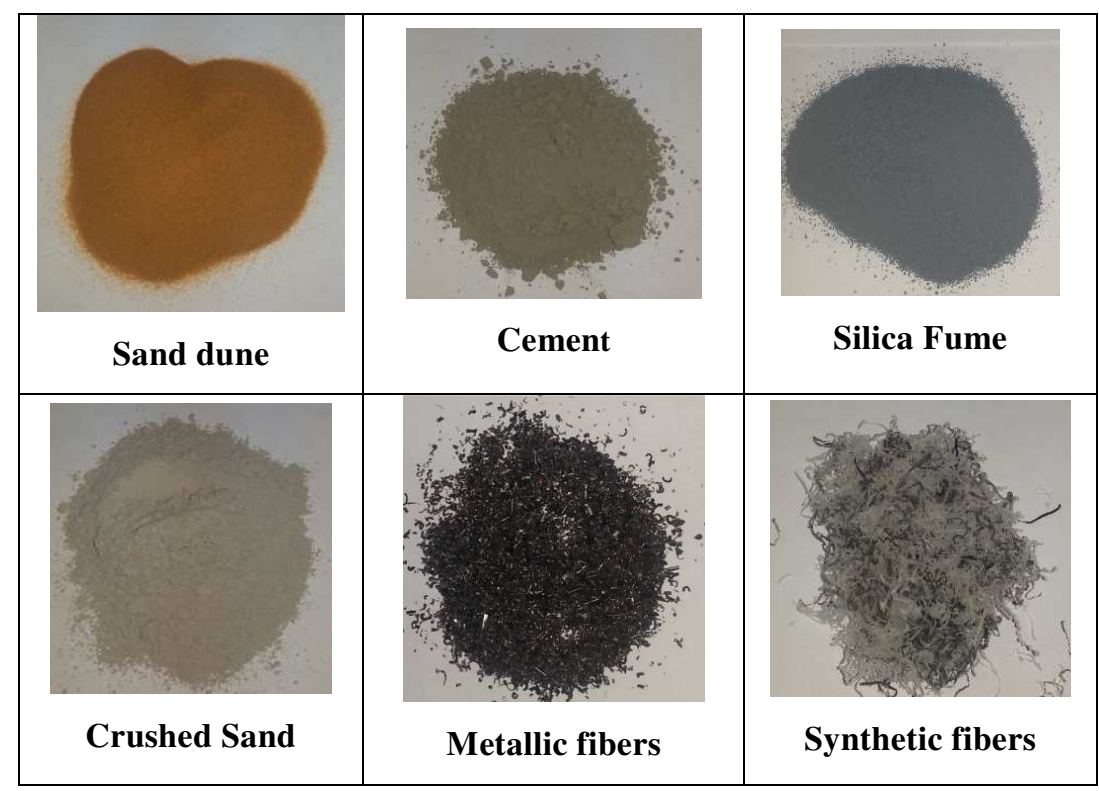

Figure 1: Materials Used

Table1: Physical Property of Cement and Sand Crushed

\begin{tabular}{|l|c|c|c|}
\hline & $\begin{array}{c}\text { Apparent } \\
\text { density }\end{array}$ & Specificdensity & Fineness \\
\hline CЕM П/B42.5 & 1030 & 3060 & 3242 \\
\hline $\begin{array}{l}\text { Crushed Sand } \\
\text { Dune }\end{array}$ & 1150 & 2650 & 3000 \\
\hline
\end{tabular}


Table2: Composition Mineral of the Cement (\%).

\begin{tabular}{|c|c|c|c|c|}
\hline Cement Type & $\mathbf{C}_{3} \mathbf{S}$ & $\mathbf{C}_{2} \mathbf{S}$ & $\mathbf{C}_{3} \mathbf{A}$ & $\mathbf{C}_{4} \mathbf{A F}$ \\
\hline СЕМ П/B42.5 & 55.41 & 13.65 & 2.25 & 14.83 \\
\hline
\end{tabular}

Table3: Analyze Chemical of Cement and Sand of Dune Crushed of Taghit

\begin{tabular}{|l|c|c|c|c|c|c|c|c|c|c|}
\hline \multicolumn{1}{|c|}{ Eléments } & $\mathbf{S i O}_{2}$ & $\mathbf{A l}_{2} \mathbf{O}_{3}$ & $\mathbf{F e}_{2} \mathbf{O}_{3}$ & $\mathbf{C a O}$ & $\mathbf{M g O}$ & $\mathbf{S O}_{3}$ & $\mathbf{N a}_{2} \mathbf{O}$ & $\mathbf{K}_{2} \mathbf{O}$ & autres & P. . . \\
\hline $\begin{array}{l}\text { Crushedsand } \\
\text { Dune }\end{array}$ & 97.15 & 0.79 & 0.21 & 0.11 & 0.05 & 0.14 & 0.18 & 0.02 & $<0.02$ & 0.58 \\
\hline cement & 17.49 & 4.51 & 3.02 & 62.78 & 2.5 & 2.3 & 0.05 & 0.64 & 0.02 & 8.10 \\
\hline
\end{tabular}

\section{EXPERIMENTAL METHODS}

\section{Formulation}

The formulation used is that of the author [14] presented in table 4:

Table4: Formulation of Concrete (HPC and HPCF) [14]

\begin{tabular}{|l|c|c|}
\hline Materials $\left(\mathbf{k g} / \mathbf{m}^{3}\right)$ & HPC & HPCF \\
\hline Cement & 691 & 691 \\
\hline Sand of dune & 759 & 759 \\
\hline Silica fume & 172 & 172 \\
\hline Crushed sand dune & 276 & 276 \\
\hline Super plasticizer & 37 & 37 \\
\hline Fiber & - & 138 \\
\hline Water & 200 & 240 \\
\hline
\end{tabular}

\section{Results of the Compressive Stress of the HPC and HPCF}

The stresses compressive determined by the mechanical tests are obtained according to standard NFINTO123903on test-tubes $4 \times 4 \times 16 \mathrm{~cm}$. The results are well known in the following histogram (Figure.2).

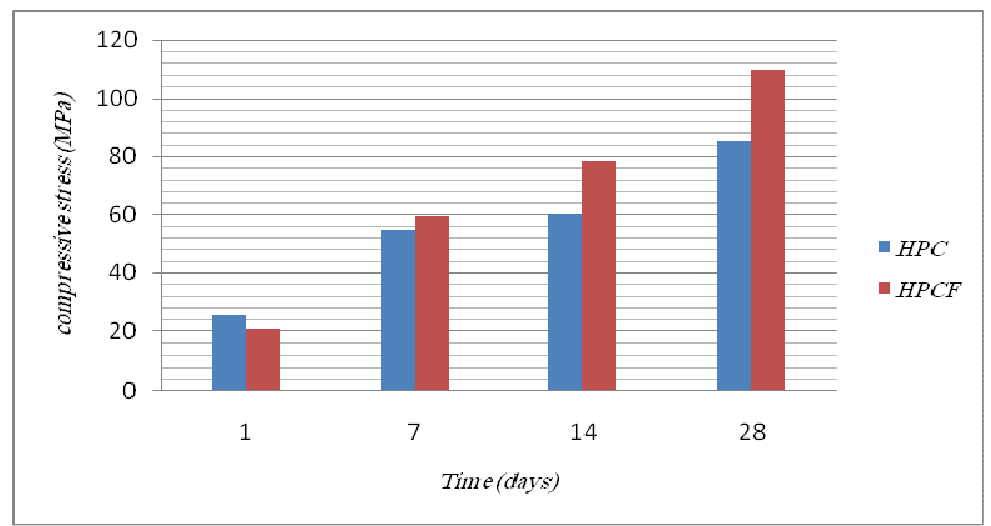

Figure 2: Histogram of the Constraint/Days.

According to the Figure.2, the HPCF reached a value of $110 \mathrm{MPa}$ at 28 days, while the HPC marked a value from approximately $90 \mathrm{MPa}$ 
The model obtained after the release from the mold is immersed in water during 3 days then treated in a drying oven with a temperaturede $150^{\circ} \mathrm{C}$ during 3 days in order to increase the mechanical properties.

\section{Principle of the Experiment}

The machining of the concrete is carried out on a universal milling machine in two parts:

Part a: Surfacing is routing by using a tool mills tow sizes diameter $50 \mathrm{~mm}$ out of metal carbide.

Part b: realization of the same operations with tool mills tow sizes of diameter $80 \mathrm{~mm}$ to plate brought back SANDVIK

\section{Machining after Treatment}

The machining of this model, Figure. 3 carries out in search of parameters of cut which give a good state of surface.

There are several criteria which make it possible to define the parameters of cut, in particular:

- $\quad$ The type of machine (turn, milling machine, drilling machine).

- $\quad$ Power of the machine.

- Machined matter

- The matter of tool (ARS carburizes...).

- The type of operation (drilling, slide-lathing, surfacing, etc.).[3, 6, 16, 17, 18]

In order to carry out the surfacing of the part, one calculates the spindle speed starting from the cutting speed such as:

$$
\begin{aligned}
& V_{c}=\omega \cdot R \quad \text { with } \omega=\frac{2 \pi N}{\omega 0}=\frac{V_{c}}{R} \\
& \text { Of Or } \\
& N=\frac{1000 V_{c}}{\pi+D}(\mathrm{tr} / \mathrm{min})
\end{aligned}
$$




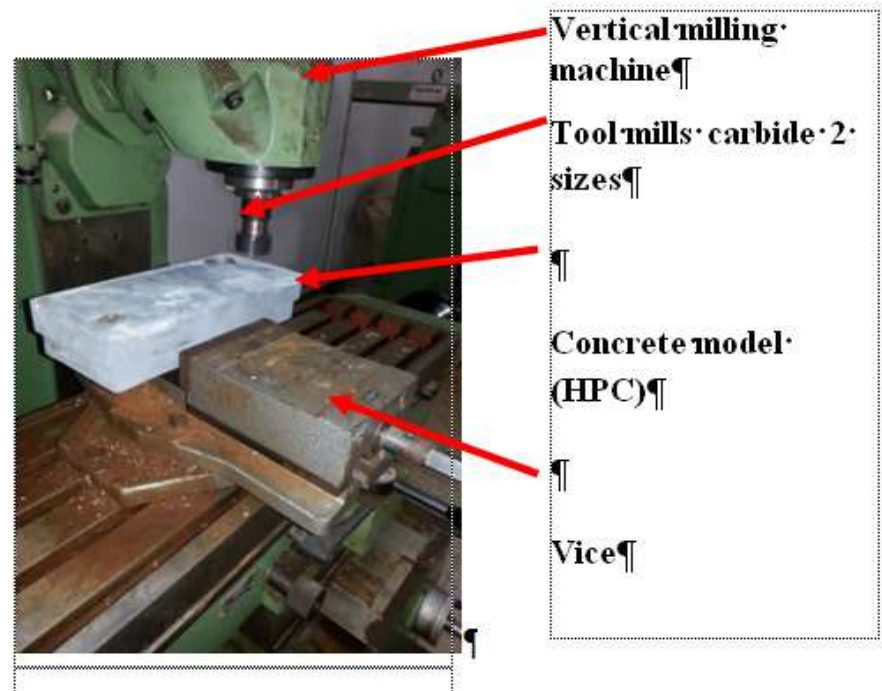

Figure 3: Surfacing of Model (HPC)

Part A: Machining with tool mills metal carbide tow size (Figure.4)

The parameters of cuts chosen for the machining of model HPC and HPCF are given in table5

Table 5: Selected Parameters of Cuts

\begin{tabular}{|l|c|c|c|c|}
\hline Opérations & $\begin{array}{c}\boldsymbol{N} \\
{[\mathbf{t r} / \mathbf{m i n}]}\end{array}$ & $\begin{array}{c}\boldsymbol{V f} \\
{[\mathbf{m m} / \mathbf{m i n}]}\end{array}$ & $\begin{array}{c}\boldsymbol{a p} \\
{[\mathbf{m m}]}\end{array}$ & show \\
\hline Test 1 & 630 & 770 & 1 & Fig. 5 \\
\hline Test 2 & 315 & 770 & 1 & Fig. 6 \\
\hline Test 3 & 160 & 770 & 1 & Fig. 7 \\
\hline Test 4 & 160 & 480 & 1 & Fig. 7 \\
\hline Test 5 & 160 & 125 & 1 & Fig. 7 \\
\hline
\end{tabular}

The operation of surfacing is made dry without lubrication, which we fixes the two parameters $(N$ and $V f)$ and we varies the depth of cut (ap), until $1 \mathrm{~mm}$ from which appears difficulties of machining. To circumvent this problem, we fixes the depth of cut at this value and speed in advance also and we makes decrease the rotational frequency of $630 \mathrm{tr} / \mathrm{min}$ with $315 \mathrm{tr} / \mathrm{min}$. Considering the hardness and the behavior of material, we always notices the existence of the difficulties of machining and the appearance of a black zone as indicates the figure below.

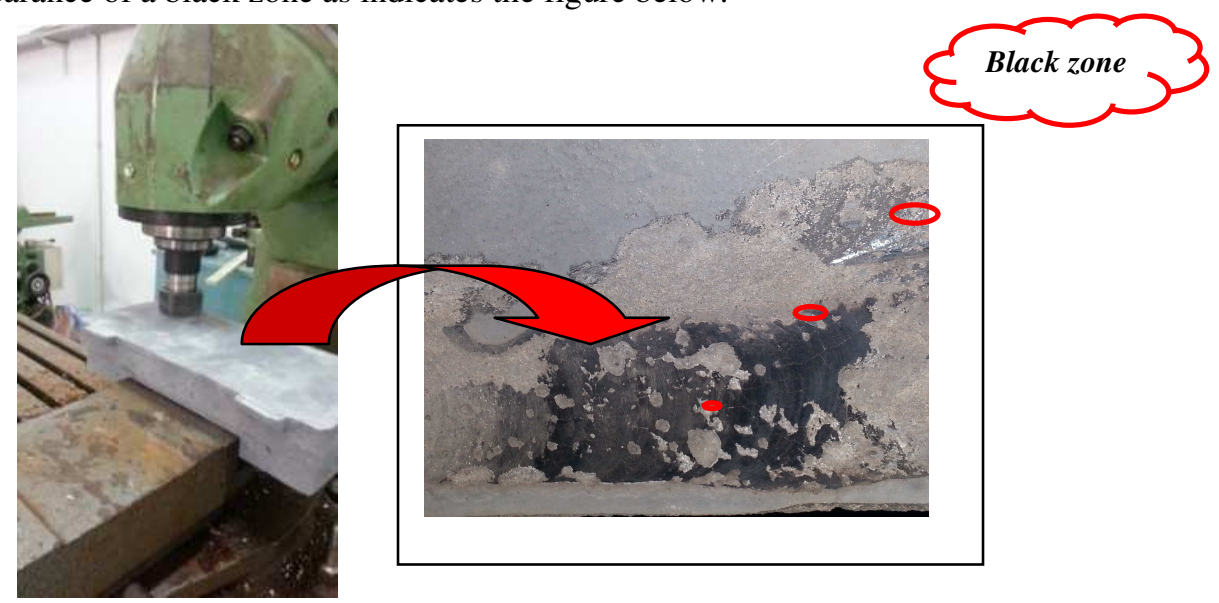

Figure 4: Operation of Surfacing 
After this operation, we can say that is the material is hard that the tool or the parameters of cuts is badly elected.

To answer this question, an operation of surfacing comes in a second test. The two parameters speed in advance are kept and depth of cut and one decreases the rotational frequency of $315 \mathrm{tr} / \mathrm{min}$ with $160 \mathrm{tr} / \mathrm{min}$ Same observations are note das in the previous tests (Figure.5 and 6). we fixes the rotational frequency at $160 \mathrm{tr} / \mathrm{min}$ and the depth of cut $1 \mathrm{~mm}$ and we decreases the speed in advance to passé from770 mm/min with $480 \mathrm{~mm} / \mathrm{min}$ then with $125 \mathrm{~mm} / \mathrm{min}$. Always the same observations (Figure.7a and b)
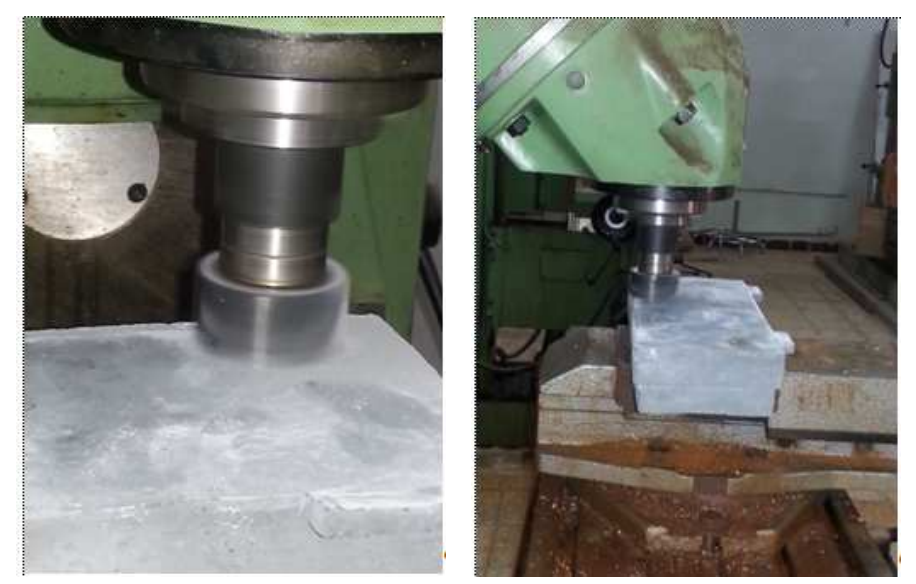

Figure 5: Operation of Surfacing Figure 6: Operation of Surfacing

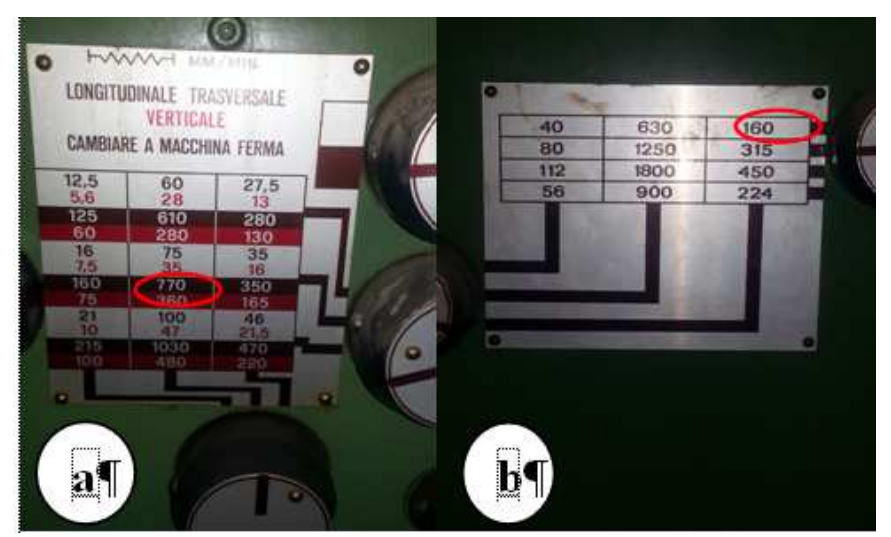

Figure.7: Variation of the Parameters of Cut, A: Rotational Frequency, B: Speed In Advance 


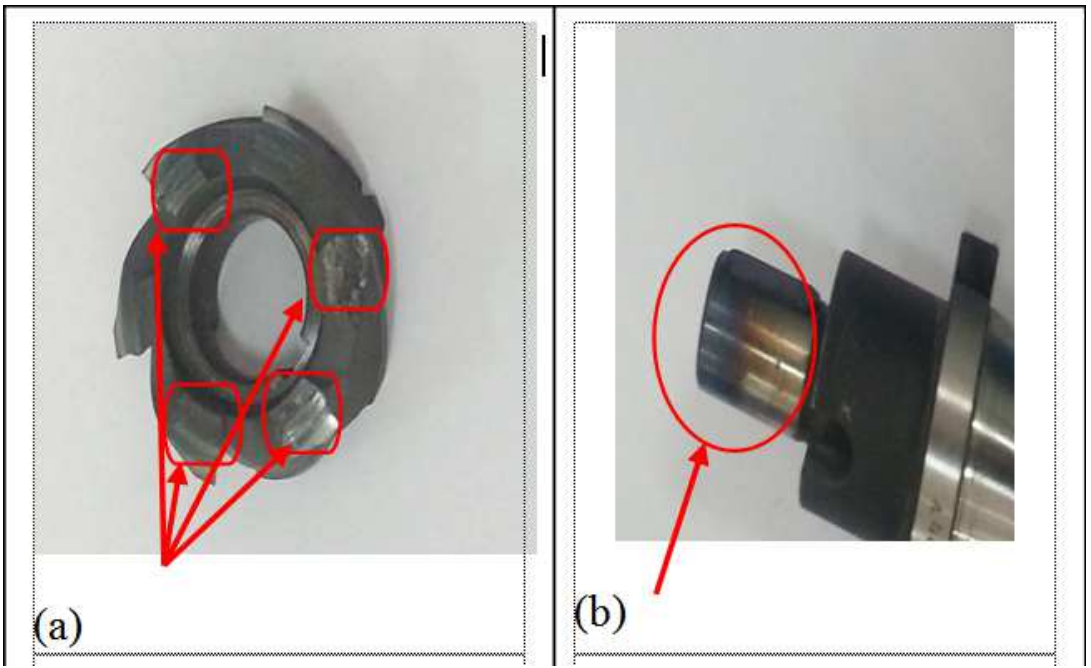

Figure8: The tool of carbide after machining (a) Stops of damaged cut, (b) Carries roasted tool.

\section{NOTICE1}

Even by decreasing the speed of the pin and in advance, we notices that the tool heated, stops it of cut is damaged and carries it tool to roasted during the operation of machining (Figure.8 a, b), the tool out of metal carbide could not machine this material and thus this tool is not appropriate because it is not harder than the concrete. The machining of model HPC and HPCF with the tool out of metal carbide did not gives at is factory results. We remakes the same operations of machining when using harder tool: a tool mills tow sizes with plates brought back SANDVICK

Part B: Machining with the tool mills with plate reported SANDVIK (Figure.9) With the same parameters of cut used previously, we carries out the machining of our material (Figure.9), we takes again the1st rotational frequency 630 $\mathrm{tr} / \mathrm{min}$ and we fixes speed in advance at $125 \mathrm{~mm} / \mathrm{min}$ and the depth of cut to $1 \mathrm{~mm}$; at the time of the first master key it there is no difficulty of machining; but for the second operation and at the end of surfacing we notes that there is a hardening surface under the friction effect tool/part from where the problem of machining, we decreases the rotational frequency of $630 \mathrm{tr} / \mathrm{min}$ with $315 \mathrm{tr} / \mathrm{min}$ even we continues with decreases the latter, the problem is not solved, we continues to decrease the number of revolution sup to $160 \mathrm{tr} / \mathrm{min}$ and the problem of machining of the concrete part is solved (Figure.12).

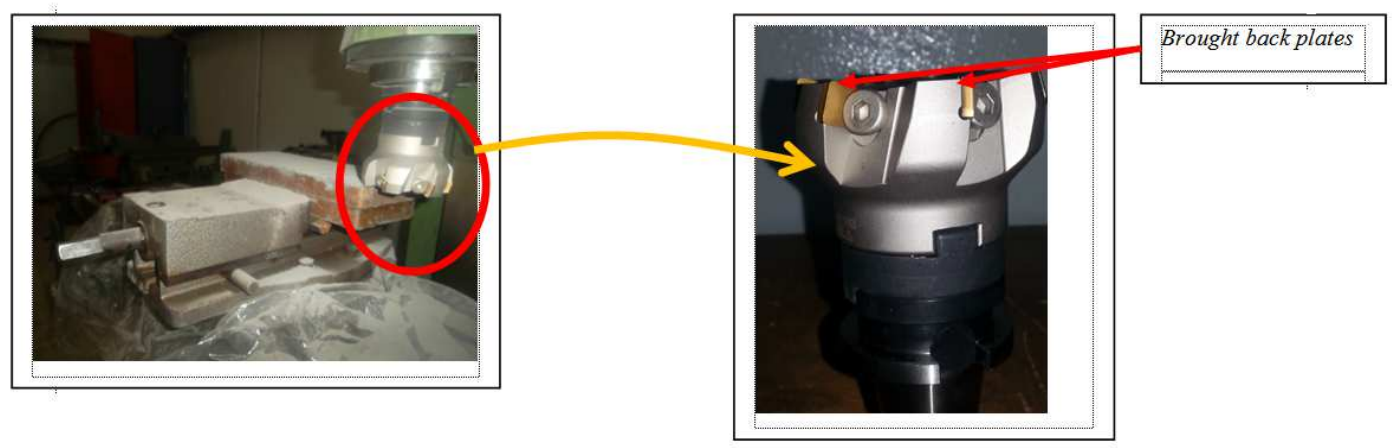

Figure 9: Operation of Surfacing

Figure 10: Tools Mills Tow Size With Plate Brought Back 


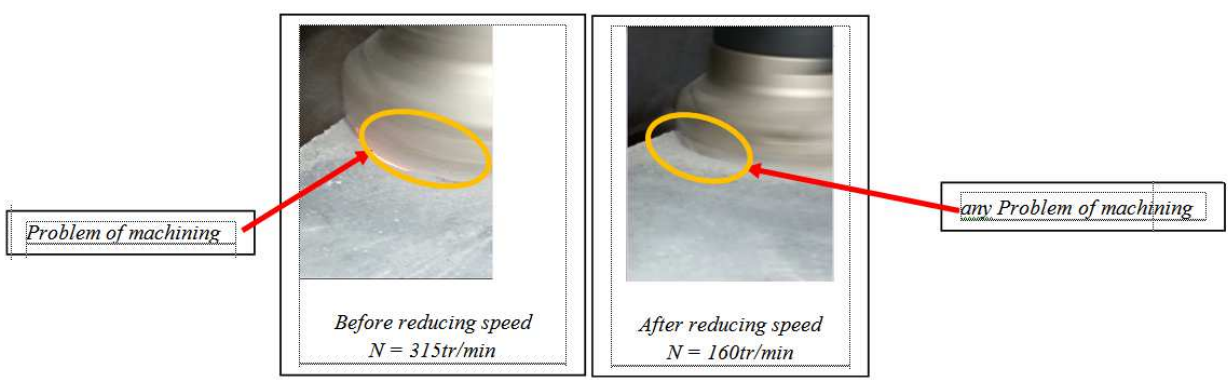

Figure11: Resolution of the problem of Machining after Reduction of the Rotational Frequency

The optimization of the parameters and cutting conditions for the machining of the concrete fiber model or not fiber with the tool mills with reported plates is obtained by carrying out several tests: The surfacing operation on the milling machine showed that machining without lubrication was difficult, to preserves top them cuts, it is necessary to decrease the heating effect by the use of lubrication. During machining with a number of revolutions of $630 \mathrm{tr} / \mathrm{min}$ we note the same difficulties, even with lubricant. By decreasing the number of revolutions with 160 tr/min, and lubrication, machining is carried out without difficulties a sin dictated by Figure.12 b, and the results are satisfactory.

\section{WE CAN THUS CALCULATE THE ADVANCE $F$ WITH THE FORMULA}

$$
V_{f}=N * f * Z \quad \text { from wheref }=\frac{v_{f}}{N * Z}=\frac{125}{160 * 6}=0.130 \mathrm{~mm}
$$

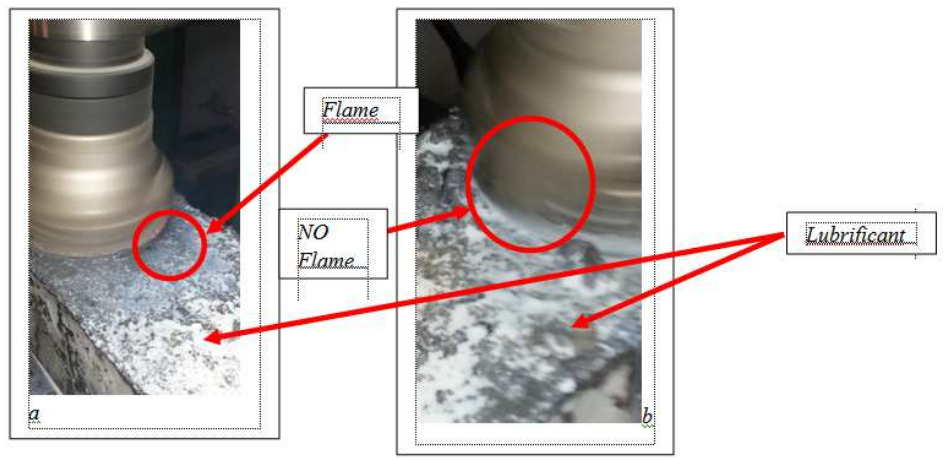

Figure12: Surfacing of Concrete HPCF

(a) Difficulty of Machining, (b) Results satisfactory.

Notice2

The surfacing operation of the Concrete model HPCF (high Concrete fiber efficiency) with milling showed that machining at a rotational frequency of $630 \mathrm{tr} / \mathrm{min}$ with or without lubricant was difficult, go around this problem it was necessary to decrease speed with $N=160 \mathrm{tr} / \mathrm{min}$ and to use lubrication, which gave good results. The selected parameters $N$ $=160 \mathrm{tr} / \mathrm{min}, V f=125 \mathrm{~mm} / \mathrm{min}$ and $a p=1 \mathrm{~mm}$ made it possible to calculate the value of the advance by tooth $f=0.130 \mathrm{~mm}$.

\section{RESULTS AND DISCUSSIONS}

Several tests were carried out to determine the parameters of cut for concrete HPC and HPCF. The operations of surfacing and routing with a tool mills tow sizes out of metal carbide with and without lubricant do not give good 
performances of machining whatever the parameters and selected cutting conditions: the composition of the concrete containing of the sand of dune characterized by the microstructure of the silica grains (very hard) and influences it heats treatment in creased the hardness of the concrete, which makes machining difficult.

For the same operations of machining with and without lubrication, by using a harder tool, tool mills has brought plates back SANDVIK, and with progressive reduction number of revolutions (until $N=160 \mathrm{tr} / \mathrm{min}$ ), speed in advance (until $V f=125 \mathrm{~mm} / \mathrm{min}$ ) and with the same depth of cut $(a p=1 \mathrm{~mm})$, we noted that machining is carried out without difficult ties and gave a good state of surface.

Influences Of The Parameters Of Cut In Operation Of Surfacing And Routing Of The Hpc And Hpcf

The parameters of chosen cut for the operation of surfacing and routing for the machining of the HPC and HPCF with the tool tow size of metal carbide always had problems even while varying the parameters and the cutting conditions.

Machining with a tool mills tow sizes with reported plates SANDVIK by optimizing the parameters and cutting conditions, gave satisfactory results.

The Influence of the Parameters of Cut on the Surface Quality

The composition of the HPC and HPCF out of quartz and silica grain gave a hardness higher than that of metal carbide tool mills what made machining difficult even by varying the parameters of cut what influenced negatively the surface quality.

Machining with a tool mills tow sizes with bringing back plates SANDVIK by choosing a number of revolutions $40 \mathrm{tr} / \mathrm{min}$ and a speed in advance $125 \mathrm{~mm} / \mathrm{min}$ improved the surface quality and roughness obtained of $6.08 \mu \mathrm{m}$ (Figure.13, $14,15)$.

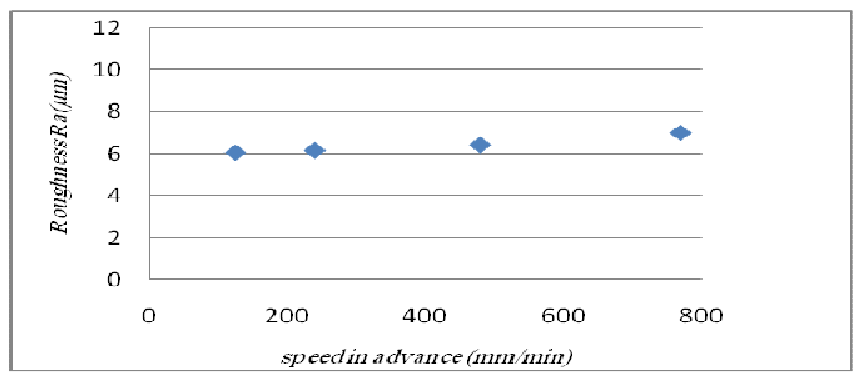

Figure13: Evolution of Roughness Ra According to Speed in Advance

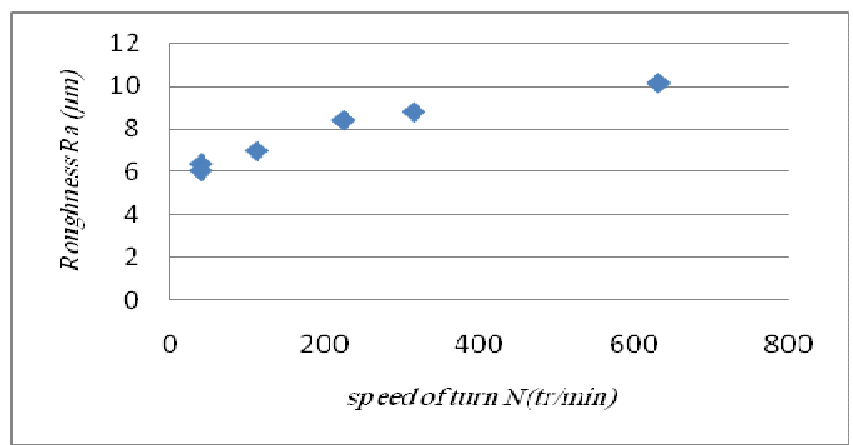

Figure14: Evolution of Roughness Ra According to the Number of Turn 


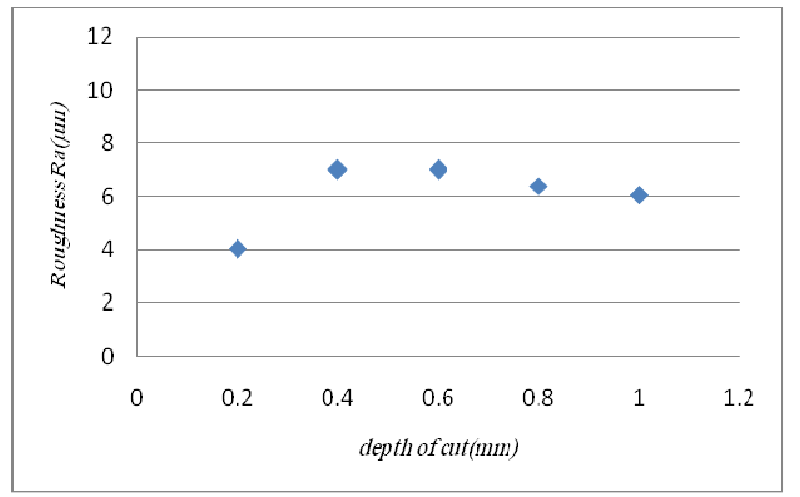

Figure15: Evolution of Roughness Ra According to the Depth of Cut

\section{CONCLUSIONS}

The objective of this work is, to seek the parameters and the conditions of cut, during the machining of a composite material concrete (HPC and HPCF), for the realization of a concrete mold for the execution of a composite material. The given experimental plan is satisfactory, it makes it possible to choose the cutting conditions, best adapted to avoid the defects of machining of this material and to increase the productivity. The machining of this kind of concrete is practically impossible, by a tool out of metal carbide, because the tool is less hard than the surface; machining with a treatment or not, even while varying the parameters and the cutting conditions. The observations made during machining it is the wear of the active part of the tool, fits netting carries tool well as the appearance of a black zone, on the level of the machined surface. The machining of this concrete required a tool in material harder as SANDVIK, which could remove the matter without difficulties. The tests carried out with a tool mills tow sizes, with reported plates SANDVIK made it possible to optimize the parameters of cut, which led to calculate value of the advance by tooth, which is a parameter having a great influence on the machined surface quality.

The tests carried out leads us to fix the parameters and the specific cutting condition shaves this kind of concrete: a number of revolutions of $160 \mathrm{tr} / \mathrm{min}$, a speed in advance of $125 \mathrm{~mm} / \mathrm{min}$ and a depth of cut de1 mm. To improve the surface quality, we decrease the number of revolutions of the finishing cut to $40 \mathrm{tr} / \mathrm{min}$, to obtain a roughness of $6.08 \mu \mathrm{m}$.

\section{REFERENCES}

1. C. Bathias et coll., Matériaux composites, Editions Dunod, ISBN 2100063987,2005

2. L. Berreur, B. de Maillard, S. Nösperger, L'industrie française des matériaux composites. Etude prospective composites, rapport de synthèse pour le compte de la DiGITIP / SIM, 2002

3. N. Bhatnagar, N. Ramakrishnan, N. K. Naik, R. Komanduri, On the machining of fibre reinforced plastic (FRP) composite laminate, International journal of machine tools and manufacture, vol. 35, p.701-716, 1994

4. C. Binétruy, Physique du moulage des composites avancés : applications, Techniques de l'ingénieur, AM3719, 2006

5. C. Bonnet, Compréhension des mécanismes de coupe lors du perçage de l'empilage Ti6Al4V / Composite fibre de carbone, Thèse de doctorat de l'Ecole Nationale Supérieure d'Arts et Métiers, 2010.

6. Z. Bouaziz, J. B. Younes, A. Zghal, Methodology of machining costs evaluation for die and mould manufacturing, Journal of Materials Processing Technology, vol. 152, p. 237-245, 2004.

7. K. D. Bouzakis, P. Aichouch, K. Efstathiou, Determination of the chip geometry, cutting force and roughness in free form surfaces finishing milling, with ball end tools, International Journal of machine tools and manufacture, vol. 43, p. 499-514, 
2003

8. Chung-Shin Chang, Turning of glass-fiber reinforced plastics materials with chamfered main cutting edge carbide tools, Journal of materials processing technology, vol. 180, p. 117-129, 2006

9. G. Chardon, H. Chanal, A. Gazel, E. Duc, Etude prospective sur l'usinage de forme de matériaux composites, $11^{\text {ème }}$ Colloque National AIP Primeca, La Plagne, France, Avril 22-24, 2009

10. G. Chardon, H. Chanal, A. Gazel, E. Duc, Prospective study on the surface machining of fiber reinforced composites, $12^{\text {th }}$ CIRP Conference on Modelling of Machining Operations, Donastia-San Sebastian, Spain, May 7-8, 2009

11. G. Chardon, H. Chanal, E. Duc, Usinage de finition de moules en matériaux composites avec outil hémisphérique : mise en évidence d'un seuil de rugosité, Intercut 2010 - $6^{\text {ème }}$ assises MUGV, Cluny, France, Octobre 13-15, 2010

12. G. Chardon, H. Chanal, E. Duc, Finishing process of mold in composites material with an abrasive diamond tool, IDMME2010, Bordeaux, France, October 20-22, 2010

13. G. Chardon, H. Chanal, E. Duc, Surface finishing of mold in fiber reinforced composites with a ball end cutter tool: detection of a minimum reachable value of roughness, Eighth International Conference on High Speed Machining, Metz, France, December 8-10, 2010

14. TAFRAOUI, Gilles Escadeillas, Thierry Vidal ; Durability of the Ultra High Performances Concrete containing metakaolin; Article history: Received 5 April 2014 Received in revised form 3 February 2016 Accepted 23 February 2016

15. M. Haddad, R. Zitoune, F. Eyma, B. Castanié. Influence of Machining Process and Machining Induced Surface Roughness on Mechanical Properties of Continuous Fiber Composites. Experimental Mechanics, 2015, Volume 55, Number 3

16. C. L. Walters. The Effect of Machining the Gage Section on Biaxial Tension/Shear Plasticity Experiments of DP780 Sheet Steel. Experimental Mechanics, 2013, Volume 53, Number 9

17. J. Xiong, B. Wang, L. Ma, J. Papadopoulos, A. Vaziri, L. Wu. Three-dimensional Composite Lattice Structures Fabricated by Electrical Discharge Machining. Experimental Mechanics, 2013, Page 1

18. H. Z. Jishi, R. Umer, W. J. Cantwel. The fabrication and mechanical properties of novel composite lattice structures. Materials \& Design Volume 91, 5 February 2016 
